\title{
Minimizing total costs of forest roads with computer-aided design model
}

\author{
ABDULLAH E AKAY \\ Kahramanmaras Sutcu Imam University, Faculty of Forestry, Department of \\ Forest Engineering, 46100 Kahramanmaras, Turkey \\ e-mail: akay@ksu.edu.tr
}

MS received September 2005; revised 13 June 2006

\begin{abstract}
Advances in personal computers (PCs) have increased interest in computer-based road-design systems to provide rapid evaluation of alternative alignments. Optimization techniques can provide road managers with a powerful tool that searches for large numbers of alternative alignments in short spans of time. A forest road optimization model, integrated with two optimization techniques, was developed to help a forest road engineer in evaluating alternative alignments in a faster and more systematic manner. The model aims at designing a path with minimum total road costs, while conforming to design specifications, environmental requirements, and driver safety. To monitor the sediment production of the alternative alignments, the average sediment delivered to a stream from a road section was estimated by using a road erosion/delivery model. The results indicated that this model has the potential to initiate a new procedure that will improve the forest road-design process by employing the advanced hardware and software capabilities of PCs and modern optimization techniques.
\end{abstract}

Keywords. Forest engineering; road design; optimization; road cost; sediment prediction.

\section{Introduction}

Designing low volume forest roads in mountainous terrain involves various economic and environmental requirements. The costs of construction and maintenance of a forest road are generally the largest cost components in producing timber for industrial uses. Besides, forest roads potentially result in more sediment production than any other timber-harvesting operation (Skaugset \& Allen 1998). Thus, road managers must consider as many alternative alignments as possible to locate a feasible road alignment that minimizes construction and maintenance costs and reduces environmental impacts.

Optimization techniques can be used to systematically search for an optimum road alignment at minimum cost and with reduced environmental impact. In highway construction, there have been various examples of road design systems using modern optimization techniques (Mayer et al 1981; Easa 1987, 1988; Goh et al 1988; Chew et al 1989), while optimization 
techniques have been recently used in a few forest road design systems (Ichihara et al 1996; Tan 2000; Anderson \& Nelson 2004).

There are commonly used computer-aided forest road design systems such as RoadEng (Oregon) and Lumberjack (Washington); however, they still do not use optimization techniques to minimize the total cost of construction, maintenance, and transportation, or consider environmental impact. Besides, to compute earthwork allocation, these systems employ the mass-haul diagram method, which is limited in cases where soil types change along the roadway (Easa 1987).

A forest road optimization model has been developed to design an optimal alignment that minimizes the sum of construction, maintenance and transportation costs, while considering design specifications, environmental requirements, and driver safety (Akay \& Sessions 2005). The main geometric specifications considered in the model are maximum road gradient, minimum horizontal curve radius, and minimum vertical curve length. The environmental requirements include minimum road gradient to provide suitable drainage, minimum stream-crossing angle to protect stream channels, and maximum allowable heights for cuts and fills to decrease potential soil movement. Driver safety is ensured by considering safe-stopping distance.

In the model, a designer first manually selects an initial trial route by establishing a series of intersection points on a 3D image of the terrain and then the model automatically locates the horizontal and preliminary vertical alignment, calculates total costs, and estimates sediment production from the road section, considering specified design constraints. Finally, the optimal vertical alignment with minimum total cost is selected among a large number of feasible alignment alternatives by using a simulated annealing algorithm, which is one of the widely used combinatorial optimization techniques. For each vertical alignment, the model minimizes earthwork costs using linear programming, which considers various soil types along the road section (Mayer \& Stark 1981).

In this study, the methodology behind some of the key components of the model, including specified design constraints, road costs, and sediment prediction are presented in detail. The optimization capabilities of the model is described briefly here since they have been discussed in detail elsewhere (Akay 2004). Some suggestions for future studies are also provided.

\section{Model formulation}

This section presents the methodology of the model (figure 1). In the model, the user first provides the required input data, including the high-resolution digital elevation model (DEM), soil types, and stream data. DEM is used to generate the 3D view of the terrain on the computer screen, so the user can select control points interactively using the mouse. Various soil type data are used to reflect some of the factors such as cut and fill slope, unit costs of road construction activities, road surfacing, and sediment prediction. Stream data is used to determine the amount of sediment that reaches the stream channel. Then, the user enters road design standards (road surface type, road template specifications, distance between road stations, design speed, vehicle specifications, traffic volume etc.), economic data (the unit costs of road construction and maintenance activities, machine rate components of specified vehicles etc.), and local data (soil swell and shrinkage factors, ground cover type, geological data, stand data, distance to resources of road construction materials etc.).

\subsection{Design constraints}

In the model, design constraints are evaluated in real time. This section reviews the mathematical formulation for each road design constraint using the following nomenclature where 


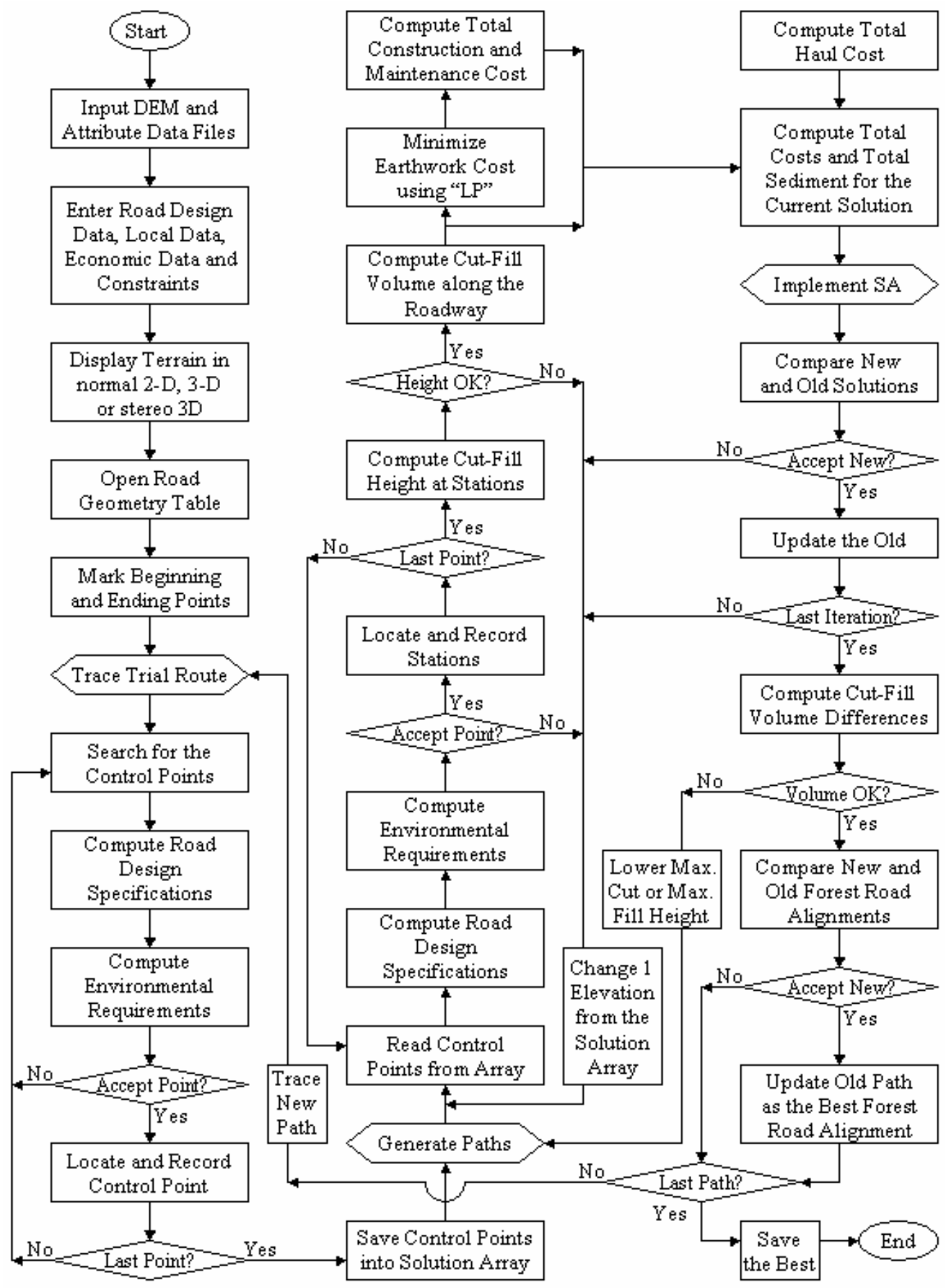

Figure 1. Theory of the forest road alignment model. 


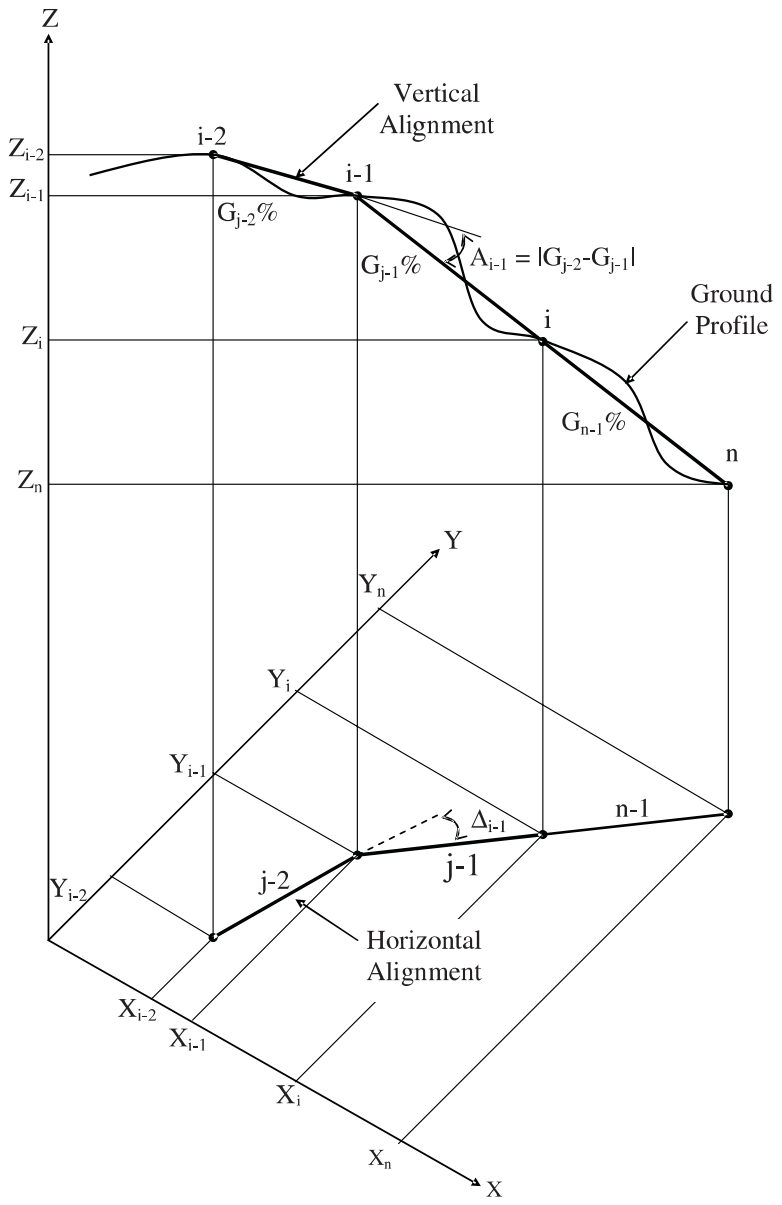

Figure 2. Horizontal and vertical road alignments.

$i$ is the currently evaluated candidate point, while $i-1$ and $i-2$ refer to the previously selected control points (figure 2):

$G_{j}$ road grade at tangent $j$ in percent,

$A_{i}$ absolute value of the difference between $G_{j}$ and $G_{j+1}$ at control point $i$,

$i$ the parameter for numbering the control points,

$j$ the parameter for numbering the roadway grades (tangents),

$n$ number of control points on some particular project,

$X_{i}$ centreline coordinate of $X$ axis at control point $i$,

$Y_{i}$ centreline coordinate of $Y$ axis at control point $i$,

$Z_{i}$ centreline elevation at control point $i$,

$\Delta_{i}$ horizontal deflection angle in degree at control point $i$.

\subsection{Road grade}

A negative road grade in the direction of an unloaded log truck is limited by the maximum allowable road grade, $G_{f}$, considering the ability of a loaded log truck travelling on this grade 
uphill from the landing area. A positive grade in the direction of an unloaded log truck is limited by the maximum allowable road grade, $G_{a}$, considering the ability of an unloaded log truck to negotiate this uphill grade. The road grade is also limited by the minimum acceptable road grade, $G_{\min }$, to provide proper drainage.

\subsection{Curvature}

The model calculates $A_{i-1}$ and $\Delta_{i-1}$ to determine whether any type of curve is necessary.

$$
\begin{aligned}
& A i-1=|G j-1-G j-2|, \\
& \Delta i-1=\arctan \left(\frac{|Y i-1-Y i-2|}{|X i-1-X i-2|}\right)-\arctan \left(\frac{|Y i-Y i-1|}{|X i-X i-1|}\right) .
\end{aligned}
$$

For low volume forest roads, it is not necessary to locate a vertical curve if $A_{i-1}$ is less than or equal to a specified small percentage of difference in grades, $A_{\min }$ (e.g. $\leq 5 \%$ ). If $A_{i-1}$ is greater than $A_{\min }$ and $\Delta_{i-1}$ is zero, the model locates a vertical curve. If $A_{i-1}$ is less than or equal to $A_{\min }$ and $\Delta_{i-1}$ is greater than zero, then the model locates a horizontal curve. Otherwise, a straight segment (tangent) is located. If there is a case where $A_{i-1}$ is greater than $A_{\min }$ and $\Delta_{i-1}$ is greater than zero, the model warns the designer to choose a different control point that avoids the overlapping of vertical and horizontal curves.

\subsection{Vertical curve}

The primary challenge of locating vertical curves is generating a sufficient curve length that permits a log truck to pass a curve without bottoming out in the sag or breeching the crest and provides safe stopping distance, SSD. Thus, the model locates a vertical curve that accommodates an adequate curve length to ensure a safe roadway passage. The minimum curve length $\left(L v_{\min }\right)$ of a forest road is usually considered to be 15 metres (USDA Forest Service 1987). When the final tangent grade, $G_{j-1}$, is less than the initial tangent grade, $G_{j-2}$, a crest curve occurs, and when $G_{j-1}$ is greater than $G_{j-2}$, a sag curve occurs. Figure 3 illustrates the geometry of a vertical crest curve, generated based on three consecutive control points. In this figure, $L v_{i-1}$ is the length of the curve, $B V C_{i-1}$ is the beginning of the curve, and $E V C_{i-1}$ is the end point of the curve.

Crest and sag vertical curves are considered separately based on whether the curve length is greater or less than the safe stopping distance (Douglas 1999). SSD is one of the primary

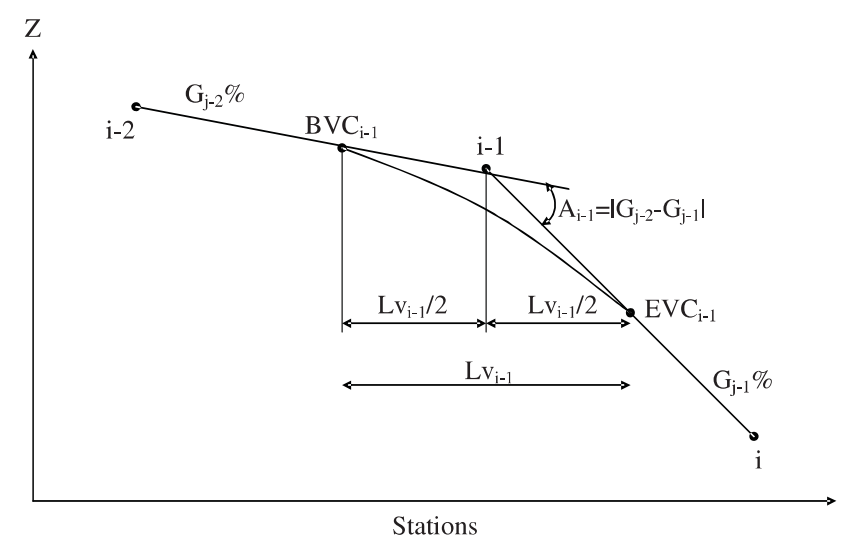

Figure 3. Symmetrical vertical curve (crest) used in the model. 
elements in designing horizontal and vertical curves with an appropriate level of safety. The objective is to provide a sufficient sight distance for drivers to safely stop their vehicles before reaching objects obstructing their forward motion. SSD is computed using (3) (AASHTO 1990). In this equation, $V$ is the design speed (kilometre per hour), $t_{r}$ is perception/reaction time of the driver in seconds (generally 2.5 seconds), $f$ is the coefficient of vehicle-braking friction, and $g$ is the road grade in decimal percent.

$$
\mathrm{SSD}=V^{2} /[254(f \pm g)]+0 \cdot 278 V t r .
$$

The required safe stopping distances for various road surface types with different braking coefficients can be obtained from AASHTO (1990). Use of a grade between zero percent and a small negative grade (e.g. - 3\%) is generally suggested (Mannering \& Kilareski 1990). By using the coordinates of the previously selected control point, $i-2$ and $i-1$, the designer searches for a third control point that generates a feasible vertical curve satisfying the geometric constraints, minimum curve length and required safe stopping distance. If the curve length is less than the user-defined minimum, the designer is warned to select a feasible candidate point. Otherwise, the candidate control point is defined as the third control point and accepted.

\subsection{Horizontal curve}

To design a feasible horizontal curve that provides safe continuous operation, geometric constraints such as minimum radius, acceptable road grade on horizontal curve, and minimum safe stopping distance must be considered. If the absolute value of the difference between grades is less than or equal to $A_{\min }$ and the horizontal deflection angle is greater than zero, the model locates a horizontal curve. Figure 4 indicates the geometry of a simple horizontal circular curve, generated based on three consecutive control points. In this figure, $\mathrm{PC}_{i-1}$ is the beginning of curve, $\mathrm{PT}_{i-1}$ is the ending of curve, $\mathrm{PI}_{i-1}$ is the point of control at control point $i-1, R_{i-1}$ is the radius measured from the centreline of the road, $T_{i-1}$ is the tangent length, $L h_{i-1}$ is the length of curve, $M_{i-1}$ is the middle ordinate, $E_{i-1}$ is the external distance, and $L C_{i-1}$ is the chord length from $\mathrm{PC}_{i-1}$ to $\mathrm{PT}_{i-1}$.

The model searches for a feasible horizontal curve that meets the geometric constraints by adjusting the tangent lengths. First, the curve radius for each tangent is computed (Anderson et al 1985):

$$
R i-1=\frac{(T i-1)}{\tan ((\Delta i-1) / 2)}
$$

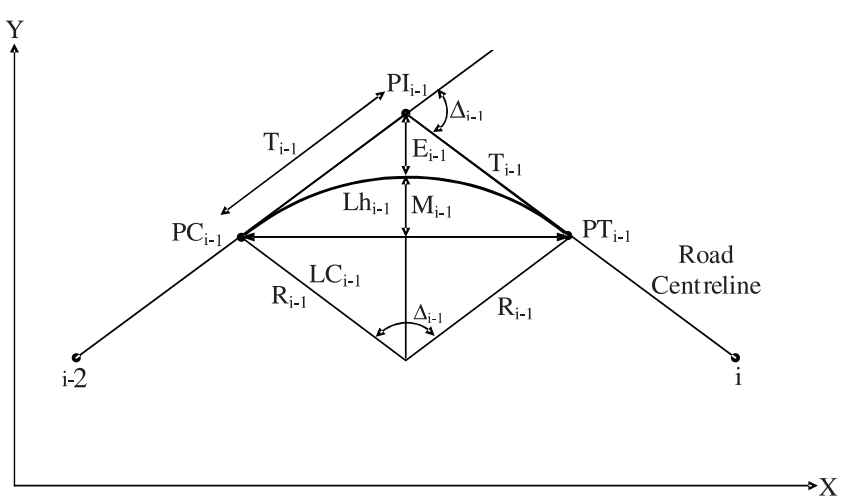

Figure 4. Simple horizontal circular curve used in the model. 
When $R_{i-1}$ is greater or equal to minimum radius, the chosen tangent length satisfies the minimum radius constraint, and the model moves to the next constraint, which is the acceptable road grade in percent on horizontal curve, $G c_{i}-1$. The model first defines the $X$ and $Y$ coordinates of $\mathrm{PC}_{i-1}$ and $\mathrm{PT}_{i-1}$, and computes the elevation of these points, $\mathrm{PC}_{i-1}$ and $\mathrm{PT} z_{i-1}$ respectively. Then, the road grade on the horizontal curve $\left(G c_{i-1}\right)$ is computed as follows:

$$
\text { Gci }-1=(P T z i-1-P C z i-1) / \text { Lhi }-1,
$$

where the length of horizontal curve $\left(L h_{i-1}\right)$ is (Anderson et al 1985):

$$
L h i-1=(\Delta i-1 \pi R i-1) / 180^{\circ} .
$$

A negative grade on a curve in the direction of an unloaded log truck is limited by the maximum allowable road grade, $G c_{f}$, considering the ability of a loaded log truck travelling on this grade uphill from the landing. A positive grade on a curve in the direction of an unloaded $\log$ truck is limited by the maximum allowable road grade, $G c_{a}$, considering the ability of an unloaded log truck to negotiate this uphill grade. The grade on the curve should be kept lower than that on a tangent because: (a) off-tracking of the vehicle creates a higher "effective" grade for both the truck and the trailer, (b) the truck incurs additional forces required to turn the tandem axles around the curve, and (c) the powered wheels may have unbalanced normal loads due to a combination of centrifugal force, superelevation, and angle of the trailer. All three factors reduce the gradeability of the vehicle. The effect of these factors is increased as the radius decreases.

If $G c_{i-1}$ satisfies the requirements of road grade on a horizontal curve, the model investigates the next constraint, which is minimum safe-stopping distance of a horizontal curve. Safestopping distance is used as a limiting factor for the curve length. If the curve length is less than the safe-stopping distance of an operating vehicle travelling at or near the design speed, the designer is warned to avoid locating this curve due to inadequate curve length. SSD is computed using (3). In this equation, the limiting speed of the vehicle around the horizontal curve $(V$ in $\mathrm{km} / \mathrm{h}$ ) can be formulated considering vehicle weight, side friction force, centrifugal force, curve radius, side friction coefficient, and super elevation. Equation (7) is the simplified form of this formulation (Mannering \& Kilareski 1990).

$$
V=11 \cdot 25(R i-1(f s+e))^{1 / 2},
$$

where $f_{s}$ is the coefficient of side friction and $e$ is the super elevation of the horizontal curve if it exists. The middle ordinate distance must be visually clear, so that the available $S S D$ is sufficient for the driver's line of sight. Experience has shown that a driver should be able to see from an eye height of $1070 \mathrm{~mm}$ and stop before hitting an object of $150 \mathrm{~mm}$ height at the mid-ordinate. On forest roads, $600 \mathrm{~mm}$ of object height at the middle ordinate point is generally used. Middle ordinate distance in metres is computed as follows (Mannering \& Kilareski 1990):

$$
M=R[1-\cos (28 \cdot 6(\mathrm{SSD} / R))] .
$$

\subsection{Stream constraints}

Since riparian forest buffers improve stream conditions by reducing erosion, improving water quality, and enhancing fish and wildlife habitat, an appropriate design should provide a sufficient distance between the foot of the fill slope and the stream (Burroughs et al 1989). The 
model provides the designer with the horizontal distance between any control point considered and the closest stream point, using the attribute data file in which $X$ and $Y$ coordinates of the stream points are stored. The stream-crossing angle is also monitored to reduce the sediment delivery and create the least amount of disturbance to the stream.

\subsection{Cut and fill height}

After connecting the two end points of the road by selecting feasible control points that satisfy the design constraints, the model stores the data for this path. Using the trial route data as an initial solution, the station points are located between the control points along the horizontal curve, vertical curve, and tangent sections. Then, cuts and fills are identified by computing the difference between ground elevation, $Z g_{p}$, and road elevation, $Z_{p}$, at each station point. If $Z_{p}$ is less than $Z g_{p}$ there is 'cut' and if $Z_{p}$ is greater than $Z g_{p}$ there is 'fill'. Otherwise, there is no cut or fill at the station. The ground elevation, as a function of $X_{p}$ and $Y_{p}$ coordinates, is obtained from the DEM data file. The cross-sectional dimensions are used to compute earthwork volume (i.e. end-area method) and major cost elements for each road stage between two consecutive stations. Both inslope and crowned type forest road surfaces are permitted. For road stages located on a horizontal curve, adequate curve widening is provided for vehicle off-tracking.

\section{Road costs}

\subsection{Construction costs}

The road construction cost is the total cost of the road construction activities: construction staking, clearing and grubbing, earthwork allocation, drainage and riprap, surfacing, water supply and watering, and seeding and mulching. The cost elements are obtained from the "Cost estimate guide for road construction region 6" (USDA Forest Service 1999). The cost guide provides standard methods for estimating road construction in the Pacific Northwest Region. The basic unit costs (profit, risk, overhead, materials, equipment, transportation, and labour costs) of the construction activities and related adjustment factors can be obtained from the data tables. Wage rates are also adjusted based on the wage ratio and labour range tables in this cost guide. Earthwork allocation and surfacing costs are discussed in the next section since they are the largest cost components.

The earthwork cost is minimized using the linear programming method of Mayer \& Stark (1981), since this model considers various soil types, swell and shrinkage factors of the material, and possible borrow and landfill locations along the roadway. In the model, the unit costs for earthwork activities (excavation, haul and embankment) vary based on the soil types. The objective function aims to minimize the total cost of earthwork allocation, subject to the following constraints (Akay 2004):

- The amount of cut moved from any cut section to any fill section plus the amount of cut moved from this cut section to a landfill area must be equal to the available amount of cut at this cut section.

- The adjusted amount of cut moved from any cut section to any fill section plus the adjusted amount of material moved from a borrow area to this fill section must be equal to the amount of fill required at this fill section. The shrinkage factors for material moved from the cut section and a borrow area are defined based on the soil type. 
- The adjusted amount of cut moved from any cut section to a landfill area must be equal to or less than the capacity of this landfill area. The swell factor for material moved from this cut section is also defined based on the soil type.

- The amount of material moved from a borrow area to any fill section must be equal to or less than the material available in this borrow area.

The surfacing cost varies depending on the type and required quantity of the surfacing material and haul distance. Rock size and the depth of the aggregate surfacing are determined based on the type of the subgrade soil along the roadway. The surfacing cost includes rock purchasing or production cost, hauling cost, processing costs (compacting, mixing, and placing) and testing cost. Multiple layers of surfacing are considered including base course and traction surface. The depth of the base course is determined based on the bearing strength of the subgrade soil. A traction surface is then placed over the base rock to increase traction and to provide a smooth durable travelling surface of low rolling resistance for rubber-tyred traffic. The rock size and depth of the traction surface can be varied by road grade.

\subsection{Maintenance costs}

Road maintenance generally consists of replacing the aggregate to preserve structural integrity and travel quality, performing blade maintenance activities, maintaining culverts, and cleaning ditches. Removing brush from both cut and fill slopes is also considered to maintain visibility. The lack of long-term prediction for road performance makes it difficult to estimate future maintenance expenditures (Christian \& Newton 1999).

Rock replacement cost is often computed depending on the timber volume transported over the road section. In the model, the amount of rock replacement material is computed based on the rock displacement in depth, road width, and length of the road stage. Then, the model computes components of the surfacing cost including rock purchasing or production cost, hauling cost, processing costs (compacting, mixing, and placing) and testing cost. Then, the rock replacement cost $\left(C_{r}\right)$ is formulated as follows:

$$
C r=\operatorname{cs}\left(V_{\text {timber }} / V_{r}\right),
$$

where $c_{s}$ is total cost of surfacing cost components, $V_{\text {timber }}$ is the timber volume transported over the road stage, and $V_{r}$ is the average volume of haul that requires at least one rock replacement operation.

The blading cost is also computed depending on the timber volume transported over the road section. The following equation is used to compute the blading $\operatorname{cost}\left(C_{b}\right)$ :

$$
C b=u b \operatorname{Lr}\left(V_{\text {timber }} / V_{b}\right),
$$

where $u_{b}$ is the basic unit cost of blading per kilometre, $L_{r}$ is the length of the road section in kilometres, and $V_{b}$ is the average volume of haul that requires at least one blading operation.

The cost of maintaining ditches $\left(C_{d}\right)$ and cleaning brush $\left(C_{c b}\right)$ is calculated depending on their basic unit costs per kilometre and length of the road section to be maintained. The cost of maintaining culverts $\left(C_{m c}\right)$ is computed by multiplying the basic unit cost of maintaining a culvert by the number of culverts installed along the roadway. The unit cost of these activities can be obtained from local economic data. Culvert and ditch maintenance, and brush cleaning take place in time intervals of $t_{m}$. 
Finally, the present value of future maintenance costs, $M_{0}$, is computed using a terminating periodic series approach (Klemperer 1996):

$$
M 0 \approx(C r+C b)\left[\frac{1-(1+r)^{-n}}{(1+r)^{t}-1}\right]+(C d+C c b+C m c)\left[\frac{1-(1+r)^{-n}}{(1+r)^{t_{m}}-1}\right],
$$

where $r$ is annual interest rate, $t$ is harvesting periods in years, and $n$ is estimated total service time of the road in years or the time when the last harvesting has occurred.

\subsection{Transportation costs}

Transportation costs mainly vary with truck performance and the hourly cost of the truck with operator (machine rate). Vehicle performance is calculated in terms of design speed, entering and exit speed, and acceleration and deceleration rates of truck traffic. The effect of gradient and curvature on truck travel time is considered for each road section. The machine rate is divided into ownership, operating and labour costs. Fuel and tyre costs are computed separately and then added into the total transportation cost. After determining the truck speed based on the vehicle performance, gradient, and curvature, the total truck travel time ( $t_{t r v}$ in hour) is computed as follows:

$$
t_{t r v}=\operatorname{Lr}((V L+V U L) / V L V U L)(1+t d),
$$

where $L_{r}$ is the length of the road section in kilometres, $V_{L}$ and $V_{U L}$ are loaded and unloaded truck speeds in kilometers per hour respectively, and $t_{d}$ is the estimated delay time during the travel in percent. Then, the future cost of the transportation is computed using the following equation:

$$
C_{t}=t_{t r v}\left(V_{\text {timber }} / \text { Load }\right) M R+C_{\text {fuel }}+C_{\text {tyre }}
$$

where Load is the average load capacity of the truck in cubic metres, $V_{\text {timber }}$ is the timber volume transported over the road section, and MR is the machine rate. The straight-line method is used to compute the machine rate. The fuel cost $\left(C_{\text {fuel }}\right)$ and tyre cost $\left(C_{\text {tyre }}\right)$ are computed based on fuel consumption rate and tyre wear rate respectively. The present values of the future transportation costs are computed using a terminating periodic series approach (Klemperer 1996):

$$
T_{0} \approx(C t)\left[\left\{1-(1+r)^{-n}\right\} /\left\{(1+r)^{t}-1\right\}\right] .
$$

\section{Sediment production}

The model estimates average annual volume of sediment delivered to a stream from the road segments, using the GIS-based road erosion/delivery model, SEDMODL (Boise Cascade Corporation 1999). This model is a slightly modified version of the Washington Department of Natural Resources surface erosion module (WDNR 1995). Road erosion factors considered in this model include geologic erosion rate, road surface type, traffic density, road width and length, average road slope, average precipitation factor, distance between road and stream, cut slope cover density, and cut slope height.

Tread and Cutslope Sediment $=G E_{r} S_{f} T_{f} G_{f} P_{f} D_{f} L_{r} R W+G E_{r} C S_{f} h_{c} D_{f} L_{r}$ 
where geological erosion rate ( $\mathrm{kg} / \mathrm{m}^{3}$-year): $G E_{r}$, tread surfacing factor: $S_{f}$, traffic factor: $T_{f}$, road grade factor: $G_{f}$, precipitation factor: $P_{f}$, delivery factor: $D_{f}$, length of the road segment (m): $L_{r}$, road width (m): $R W$, cutslope cover factor: $C S_{f}$, and cutslope height (m): $h_{c}$. For general use, the equations are developed based on the road erosion surveys in six watersheds in Washington, Oregon, and Idaho. The values for the variables used in the formulation can be obtained from the data tables provided based on the previous researches (Boise Cascade Corporation 1999). In SEDMODL, the stream-crossing section of the road delivers directly to stream and results a delivery factor of 1 . If the road section is within $30 \mathrm{~m}$ and $60 \mathrm{~m}$ of a stream, it results in a delivery factor of 35 percent and 10 percent respectively, while sediment does not reach the stream if the road section is located further than $60 \mathrm{~m}$. The integration of the mathematical formulations used in SEDMODL into the road design model is described in detail by Akay et al (2005).

\section{Vertical alignment optimization}

The optimum vertical alignment, which minimizes the sum of construction, maintenance and transportation costs, is selected by using the simulated annealing (SA) technique. SA was developed based upon a metallurgical technique where a solid material is heated and then cooled slowly to produce the best material. SA is selected to run the optimization algorithm since it is easy to implement into computer programming. Extended information about SA can be obtained from various sources in the literature (Kirkpatrick et al 1983; Beasley et al 1993; Reeves 1993).

After initial alignment is generated by locating the control points, the model generates alternative road alignments by changing the elevation of a randomly selected control point by a specified value (e.g. \pm 0.5 metres) within the elevation range of the control points. If an alternative satisfies all the geometric and environmental constraint, the model keeps it as a feasible alternative. For each alternative, the model calculates cross sections, earthwork volumes, total road costs, and sediment delivery. Finally, the model keeps the optimum alternative that has the minimum total road costs among all the feasible alternatives.

The designer can generate a number of additional horizontal road alignments that connect the same beginning and ending points. For each horizontal road alignment, the model follows the same optimization procedure to find the optimum vertical alignment with minimum total road costs, subject to specified constraints. After determining the final vertical alignment among the optimum alternatives, the designer determines the appropriate location for a turnout, considering visibility, side slope, and road grade.

\section{Conclusions}

The computer-aided road design model described here provides the road managers with a decision-support tool for quickly evaluating alternative road alignments systematically. Therefore, road designing time is considerably reduced in the early stage of the forest road design. Physical feasibility of the forest road is ensured by automatically considering geometric specifications, environmental impacts, and driver safety. The model provides road managers with detailed estimations of the total road cots including construction, maintenance, and transportation. Besides, average sediment production from a road section to a stream channel is also computed by using a GIS-based sediment prediction model. It is anticipated that this new 
procedure, integrating advanced hardware and software capability of PCs and modern optimization techniques, can improve the forest road design process and inspire other researchers using state-of-art technology in the field of forest road design.

The model still has following limitations and opportunities for further studies:

- The model can be improved for the case where the unit costs of earthwork are not constant along the roadway, but vary with the quantity of the cut and fill.

- The model can be also improved by including optimization of the horizontal alignment instead of manually locating it.

- The model performance highly depends on the accuracy of available GIS layers of attribute data to represent ground conditions; therefore, availability of accurate GIS data is crucial for the model.

- The model can be modified to also consider a full bench-type cross-section and out-slope forest roads.

- The model can be improved by including the computation of the total water discharge, so that, the road manager can be provided by the most appropriate culvert locations and culvert sizes along the roadway.

- Other sediment prediction models (e.g. WEPP) can be integrated into the model to compare their performances and to select the one that provides better results.

- The model can be improved by locating the landslide sensitive areas and applying adequate road design standards to reduce the risk of slope failure in these areas.

\section{References}

AASHTO 1990 American association of safe highway and transportation officials. A policy on geometric design of highways and streets, Washington, DC

Akay A 2004 A new methodology in designing forest roads. Turkish J. Agricul. Forest. 28: 273-279

Akay A, Sessions J 2005 Applying the decision support system, TRACER, to forest road design. Western J. Appl. For. 20: 184-191

Akay A, Yuksel A, Reis M, Erdas O, Sessions J 2005 Selecting the optimal forest road alignment with a maximum sediment production constraint. 28th Annual Meeting of COFE (Council on Forest Engineering). Soil, Water and Timber Management: Forest Engineering Solutions in Response to Forest Regulation, California, USA, pp 302-311

Anderson A E, Nelson J D 2004 Projecting vector based road networks with a shortest path algorithm. Can. J. For. Res. 34: 1444-1457

Anderson J M, Mikhail E M, Woolnough D E 1985 Introduction to surveying (New York: McGrawHill Ryerson)

Beasley J, Dowsland K, Glover F, Manue L, Peterson C, Reeves C, Soderberg B 1993 Modern heuristic techniques for combinatorial problems (New York: Halsted, John Wiley \& Sons)

Boise Cascade Corporation 1999 SEDMODL-Boise Cascade road erosion delivery model. Technical documentation, p. 19

Bowman E H, Fetter R B 1967 Analysis for production and operations management (Irwin Series in Quantitative Analysis for Business) (New Haven, CT: Yale University Press.) p. 870

Burroughs E R, John G K 1989 Reduction of soil erosion on forest roads. Gen. Tech. Rep. INT-264. Ogden, UT: US Department of Agriculture, Forest Service, Intermountain Research Station, p. 21

Chew E P, Goh C J, Fwa T F 1989 Simultaneous optimization of horizontal and vertical alignment for highways. Transport. Res. B23: 315-329

Christian J, Newton L 1999 Highway construction and maintenance costs. Can. J. Civil Engg. 26: $445-452$ 
Douglas R A 1999 Delivery, the transportation of raw natural products from roadside to mill (New Brunswick, Canada: Fredericton)

Easa S M 1987 Earthwork allocations with linear unit costs. J. Constr. Eng. Manage. 114: 641-655

Easa S M 1988 Selection of roadway grades that minimize earthwork cost using linear programming. Transport. Res. A22: 121-136

Goh C J, Chew E P, Fwa T F 1988 Discrete and continuous models for computation of optimal vertical highway alignment. Transport. Res. B22: 399-409

Ichihara K, Tanaka T, Sawaguchi I, Umeda S, Toyokawa K 1996 The method for designing the profile of forest roads supported by genetic algorithm. J. Forest. Res. 1: 45-49

Kirkpatrick S, Gerlatt C D, Vecchi M P 1983 Optimization by simulated annealing, Science 220: 671-680

Klemperer D 1996 Forest resource economics and finance. Virginia Polytechnic Institute and State University, College of Forest and Wildlife Resources, Virginia, p. 551

Mannering F, Kilareski W 1990 Principles of highway engineering and traffic analysis (New York: John Wiley \& Sons) p. 251

Mayer R, Stark R 1981 Earthmoving logistics. J. Constr. Div. 107: 297-312

Reeves C 1993 Modern heuristic techniques for combinatorial problems. Department of Statistics and Operational Research School of Mathematical and Information Sciences, Coventry University, p. 320

Skaugset A, Marganne M A 1998 Forest road sediment and drainage monitoring project report for private and state lands in Western Oregon. Oregon Department of Forestry, Salem, OR, USA

Tan J 2000 Application of dynamic programming to optimum location of a forest road. Int. J. For. Eng. 11(2): 33-42

USDA Forest Service 1987 Road preconstruction handbook, Forest service handbook No. $7700 \cdot 56$

USDA Forest Service 1999 Cost estimate guide for road construction region 6. Cost Guide Zone 5, Davis-Bacon Area 5, Oregon

WDNR 1995 Standard methodology for conducting watershed analysis. Version 3.0. Washington Forest Practices Board 